\section{Low body temperature, a frequently observed manifestation of patients with adrenocortical insufficiency that can recover with glucocorticoid administration: case series of 15 patients}

\author{
Hiroyuki Kinoshita, ${ }^{1}$ Yukiko Shimizu, ${ }^{1}$ \\ Yoji Komiya, ${ }^{1}$ Shinsuke Takagawa,2 \\ Mutsuko Yasuda, ${ }^{1}$ Fumiatsu Yakushiji, ${ }^{1}$ \\ 1Department of Internal Medicine and \\ 2Department of Dermatology, Tokyo \\ Metropolitan Bokutoh Hospital, Tokyo, \\ Japan
}

\section{Abstract}

We first report whether adrenocortical insufficiency causes low body temperature in human subjects. We also examined the effects of inflammation on body temperature. Furthermore, we examined whether glucocorticoid administration can increase low body temperature. We examined 15 patients with adrenocortical insufficiency who were admitted to the department of endocrinology in our hospital from October 2007 to August 2011. The mean (SD) patient age was 67.4 (8.2) years. Of the patients, $3(20.0 \%)$ were women and $12(80.0 \%)$ were men, and 8 (53.3\%) had inflammation and 7 (46.7\%) did not. The numbers of patients in the inflammation group and the non-inflammation group whose body temperatures were $<36.0^{\circ} \mathrm{C}$ upon admission were $5(63 \%)$ of 8 and $5(71 \%)$ of 7 , respectively. Inflammation had little effect on body temperature. However, in the non-inflammation group, glucocorticoid significantly increased the mean (SD) body temperature from 35.7 $(0.37){ }^{\circ} \mathrm{C}$ to $36.4(0.23)^{\circ} \mathrm{C} \quad(\mathrm{P}=0.01)$. The patients with adrenocortical insufficiency exhibited low body temperature but were able to recover. To prevent adrenal crises, medical practitioners should be aware that low body temperature can occur in patients with adrenocortical insufficiency though the patients have inflammation.

\section{Introduction}

In our clinical practice, low body temperature is frequently observed as a manifestation of adrenocortical insufficiency. However, in the representative endocrinology textbooks, low body temperature has not been listed as a manifestation of adrenocortical insufficien- cy.1,2 Furthermore, in the literature search we conducted on PubMed, the results obtained no articles on studies that examined whether adrenocortical insufficiency causes low body temperature in human subjects (key words: low body temperature or hypothermia, and adrenocortical insufficiency, hypoadrenalism, or hypoadrenocorticism).

In the present study, we report a case of adrenocortical insufficiency in a patient who presented with a low body temperature. We then examined 15 patients with adrenocortical insufficiency to determine whether low body temperature is consistently manifested. We also examined the effects of inflammation on body temperature. Furthermore, we aimed to elucidate whether glucocorticoid administration can increase low body temperature.

\section{Case Report}

In January 2011, a 67-year-old man with chronic dermatitis was admitted to our hospital for general fatigue and difficulty in talking. To treat the chronic dermatitis, every day for 2 years, he used $1 \mathrm{~g}$ of $0.05 \%$ betamethasone butyrate propionate ointment, which contains $0.5 \mathrm{mg}$ of betamethasone, corresponding to 12.5 mg of hydrocortisone. However, because his skin condition had started to improve, he had stopped the use of the betamethasone for 6 months before seeking treatment at our hospital. Upon stopping the use of the ointment, the general fatigue and the difficulty in talking began, and these symptoms gradually worsened. He was therefore admitted to our hospital. At admission, he manifested a low body temperature $\left(34.0^{\circ} \mathrm{C}\right)$ and hypotension $(80 / 40 \mathrm{mmHg})$. The results of the routine urinary and blood examinations did not show any outstanding abnormalities. The results of the systemic computer tomography (CT) of the head, the chest, and the abdomen were within normal limits. However, the endocrinologic examinations revealed a pituitary-adrenocortical insufficiency based on the adrenocorticotropic hormone (ACTH) level, $3.0 \mathrm{pg} / \mathrm{mL}$ (reference range, $9-52$ $\mathrm{pg} / \mathrm{mL}$ ), and the cortisol level, $7.1 \mu \mathrm{g} / \mathrm{dL}$ (reference range, 4.5-21.1 $\mu \mathrm{g} / \mathrm{dL}$ ). A low response was detected in the corticotrophin-releasing hormone (CRH) test. A low normal response was detected in the rapid ACTH test. A normal response was detected in the continuous ACTH test. Other hormones, including thyroid hormones, were detected at normal levels.

On the basis of these results, we made a diagnosis of pituitary-adrenocortical insufficiency, probably caused by the betamethasone ointment. Glucocorticoid treatment (hydrocortisone at $10 \mathrm{mg}$ in the morning and $5 \mathrm{mg}$ in the evening) was started, and the patient's general condition improved. His body temperature
Correspondence: Hiroyuki Kinoshita, Department of Internal Medicine, Tokyo Metropolitan Bokutoh Hospital, 4-23-15 Koutoh-bashi, Sumida-ku, Tokyo 130-8575, Japan.

Tel: +81.3.3633.6151 - Fax: +81.3.3633.6173.

E-mail: hkinoshita-tky@umin.ac.jp

Key words: adrenocortical insufficiency, low body temperature, glucocorticoid, inflammation.

Contributions: HK, provided medical care, collected and summarized the data, wrote the manuscript; YS, YK, provided medical care as an internist; ST, provided medical care as a dermatologist; MY, provided medical care, collected and summarized the data; FY, provided medical care, collected the data, conducted the project.

Conflict of interest: the authors have no conflicts of interests to declare.

Received for publication: 29 September 2011. Revision received: 12 November 2011. Accepted for publication: 16 November 2011.

This work is licensed under a Creative Commons Attribution NonCommercial 3.0 License (CC BYNC 3.0)

(C) Copyright H. Kinoshita et al., 2012

Licensee PAGEPress, Italy

Endocrinology Studies 2012; 2:e2

doi:10.4081/es.2012.e2

increased to $36.8^{\circ} \mathrm{C}$, and he was discharged from our hospital. After discharge, he discontinued taking the hydrocortisone because he believed that he had become healthy, needing no medications. However, the general fatigue and the difficulty in talking recurred; therefore, he was readmitted to our hospital. At admission, his body temperature was $32.9^{\circ} \mathrm{C}$. However, with the glucocorticoid treatment, his body temperature increased to $36.5^{\circ} \mathrm{C}$. He was then discharged again.

\section{Case series of 15 patients}

From October 2007 to August 2011, 20 patients with adrenocortical insufficiency were admitted to the department of endocrinology of our hospital. Of these 20 patients, we excluded 5 because 1 was found to have hypothyroidism and 4 were taking glucocorticoids at the time of admission. Table 1 shows the 15 eligible patients with adrenocortical insufficiency. The mean (SD) age of the patients was 67.4 (8.2) years (range 56-83 years). Of the 15 patients, 3 (20.0\%) were women and $12(80.0 \%)$ were men. The underlying etiology was panhypopituitarism in 4 (26.7\%) cases, isolated ACTH deficiency in 10 (66.7\%), and Addison disease in 1 (6.7\%). We defined inflammation as a white blood cell count $>10,000 / \mu \mathrm{L}$ or a $\mathrm{C}$-reactive protein level 
$>3.0 \mathrm{mg} / \mathrm{dL}$; accordingly, at admission, 8 patients (53.3\%) had inflammation and 7 (46.7\%) did not. Body temperature was measured at the axilla. Of the 15 patients, 10 (66.7\%) presented with a body temperature $<36.0^{\circ} \mathrm{C}$ at admission. Table 2 summarizes the data of the inflammation and non-inflammation groups.

\section{Statistical analysis}

We used an unpaired $t$ test (Student $t$ test) to compare the mean body temperature between the other groups. To examine the factors that affect the mean body temperature, a multivariate linear regression analysis was performed. The independent variables included sex, age, and inflammation, whereas the dependent variable was body temperature at admission. We used a paired $t$ test to compare the mean body temperature within the same group.

All the statistical procedures were conducted using the StatView 5.0 software (SAS Institute Inc., Cary, NC, USA), and statistical significance was defined as $\mathrm{P}<0.05$.

\section{Results}

\section{Low body temperature and} inflammation in the patients with

\section{adrenocortical insufficiency}

The numbers of patients who exhibited body temperatures $<36.0^{\circ} \mathrm{C}$ at admission in the inflammation and non-inflammation groups were $5(63 \%)$ of 8 and $5(71 \%)$ of 7 , respectively (Table 2). The mean (SD) body temperatures at admission of the inflammation and non-inflammation groups were $35.4(1.94)^{\circ} \mathrm{C}$ and 35.7 $(0.37)^{\circ} \mathrm{C}$, respectively (Table 2$)$. The difference was not statistically significant as determined by the unpaired $t$ test $(\mathrm{P}=0.67)$ and the multivariate linear regression analysis $(\mathrm{P}=0.85)$ (Table 3$)$.

The results indicate that the patients with adrenocortical insufficiency manifest low body temperatures with or without inflammation. Furthermore, the results indicate that inflammation has little effect on body temperature in the patients with adrenocortical insufficiency.

\section{Low body temperature and}

\section{glucocorticoid administration}

\section{in the patients with adrenocortical} insufficiency

At discharge, no patients had inflammation. Of the 15 patients, $14(93.3 \%)$ received glucocorticoid administration at discharge but 1 (6.7\%) did not (Table 1). We compared the body temperatures at admission with those at discharge in all the 14 patients who received glucocorticoids.

In the inflammation group, the mean (SD) body temperatures at admission and at discharge were $35.4(1.94)^{\circ} \mathrm{C}$ and $36.0(0.94)^{\circ} \mathrm{C}$, respectively (Table 2 ). Because all the patients in this group experienced two things, recovery from inflammation and starting glucocorticoid administration, we then omitted to assess the results.

In the non-inflammation group, the numbers of patients who manifested temperatures $<36.0^{\circ} \mathrm{C}$ at admission and at discharge were 5 (71\%) and 0 (0\%), respectively (Table 2). The mean (SD) body temperatures at admission and at discharge were $35.7(0.37){ }^{\circ} \mathrm{C}$ and 36.4 $(0.23)^{\circ} \mathrm{C}$, respectively (Table 2$)$. The difference was statistically significant $(\mathrm{P}=0.01$; Table 3 ).

These results indicate that glucocorticoid administration increases the body temperatures of the patients with adrenocortical insufficiency.

\section{Discussion}

Here, we report a patient with a low body temperature. After his condition was diagnosed

Table 1. Description of the 15 patients.

\begin{tabular}{|c|c|c|c|c|c|}
\hline Patients & Etiology & Inflammation & $\begin{array}{l}\text { BT } \\
\text { at admission }\end{array}$ & $\begin{array}{c}\text { BI } \\
\text { at discharge }\end{array}$ & $\begin{array}{l}\text { Steroid } \\
\text { at discharge }\end{array}$ \\
\hline $57 \mathrm{~F}$ & Pan & + & 37.9 & 36.3 & + \\
\hline $60 \mathrm{M}$ & $\mathrm{IAD}$ & + & 35.1 & 32.4 & - \\
\hline $83 \mathrm{M}$ & $\mathrm{IAD}$ & + & 37.2 & 36.1 & + \\
\hline $60 \mathrm{M}$ & $\mathrm{IAD}$ & + & 33.8 & 34.2 & + \\
\hline $61 \mathrm{M}$ & $\mathrm{IAD}$ & + & 35.2 & 36.6 & + \\
\hline $74 \mathrm{M}$ & IAD & + & 32.6 & 35.4 & + \\
\hline $71 \mathrm{M}$ & $\mathrm{IAD}$ & + & 37.5 & 36.8 & + \\
\hline $67 \mathrm{M}$ & $\mathrm{IAD}$ & + & 34.0 & 36.8 & + \\
\hline $60 \mathrm{M}$ & Pan & $-\quad$ & 36.1 & 36.3 & + \\
\hline $70 \mathrm{~F}$ & Pan & - & 35.5 & 36.3 & + \\
\hline $77 \mathrm{M}$ & Pan & - & 35.9 & 36.2 & + \\
\hline $69 \mathrm{M}$ & IAD & - & 35.7 & 36.9 & + \\
\hline $69 \mathrm{M}$ & $\mathrm{IAD}$ & - & 36.2 & 36.3 & + \\
\hline $56 \mathrm{M}$ & IAD & - & 35.1 & 36.5 & + \\
\hline $77 \mathrm{~F}$ & Addison & - & 35.7 & 36.4 & + \\
\hline
\end{tabular}

F, female; M, male; PAN, panhypopituitarism; IAD, isolated adrenocortical deficiency; BT, body temperature at the axilla; +, present; -, absent.

Table 2. Summary of the group characteristics of the 15 patients.

\begin{tabular}{lcccc} 
Group & BT at admission & $<36.0, \mathrm{n}(\%)$ & BT at discharge & $<36.0, \mathrm{n}$ \\
& & & & \\
Inflammation (n=8) & $35.4(1.94)$ & $5(63)$ & $36.0(0.94)^{*}$ & $2(29)^{*}$ \\
No inflammation (n=7) & $35.7(0.37)$ & $5(71)$ & $36.4(0.23)$ & $0(0)$ \\
\hline
\end{tabular}

Body temperature at the axilla (BT) is expressed in mean $(\mathrm{SD})^{\circ} \mathrm{C}$. ${ }^{*}$ One patient who did not receive glucocorticoids at discharge was excluded.

Table 3. Comparison of the body temperatures.

\begin{tabular}{|c|c|c|}
\hline $\begin{array}{l}\text { a. Inflammation and no inflammation } \\
\text { Univariate analysis (unpaired } t \text { test) } \\
\text { Inflammation }(\mathrm{n}=8)\end{array}$ & No inflammation $(\mathrm{n}=7)$ & P value \\
\hline BT at admission & $35.7(0.37)$ & 0.67 \\
\hline $\begin{array}{r}\text { Multivariate analysis (linear regression) } \\
\text { Regression coefficient }\end{array}$ & Confidence interval & P value \\
\hline Sex (0 women, 1 man) & -3.14 to 1.23 & 0.36 \\
\hline Age, $y$ & -0.96 to 0.12 & 0.80 \\
\hline Inflammation ( 0 absent, 1 present)- 0.16 & -1.92 to 1.60 & 0.85 \\
\hline $\begin{array}{l}\text { b. Before and after glucocorticoid administa } \\
\text { Univariate analysis (paired } t \text { test) } \\
\qquad \text { Before glucocorticoid ( } n=7)\end{array}$ & After glucocorticoid $(n=7)$ & P value \\
\hline $35.7(0.37)$ & $36.4(0.23)$ & 0.01 \\
\hline
\end{tabular}

Body temperature at the axilla (BT) is expressed in mean $(\mathrm{SD})^{\circ} \mathrm{C}$. 
as pituitary-adrenocortical insufficiency and glucocorticoid administration, his low body temperature improved. However, because he discontinued taking the glucocorticoid, the low body temperature recurred. Nonetheless, readministration of the glucocorticoid improved his low body temperature. In this case series, $>60 \%$ of the patients manifested body temperatures $<36.0^{\circ} \mathrm{C}$ at admission whether or not inflammation was present. Furthermore, inflammation had little effect on the body temperatures. However, the glucocorticoid administration significantly increased the body temperature of the patients with adrenocortical insufficiency.

\section{Low body temperature and inflammation in the patients with adrenocortical insufficiency}

On the basis of our results, $>60 \%$ of the patients with adrenocortical insufficiency manifested body temperatures $<36.0^{\circ} \mathrm{C}$ with or without inflammation. Furthermore, our results indicated that inflammation had little effect on the body temperatures of the patients with adrenocortical insufficiency. The pituitary adrenocortical axis plays important roles in various stress responses, including thermogenesis. Glucocorticoid is probably necessary for thermogenesis occurring in response to the inflammation stress. To prevent adrenal crises, medical practitioners should be aware that low body temperature can occur in patients with adrenocortical insufficiency though the patients have inflammation.

\section{Glucocorticoid administration increased the body temperatures of the patients with adrenocortical insufficiency}

Our results show that glucocorticoid administration significantly increased the body tem- peratures of the patients with adrenocortical insufficiency. In particular, $71 \%$ of the patients in the non-inflammation group manifested body temperatures $<36.0^{\circ} \mathrm{C}$ at admission. However, after glucocorticoid administration, the body temperatures of all the patients increased to $\geq 36.0^{\circ} \mathrm{C}$ at discharge. Because body temperature plays essential roles in metabolism and homeostasis, it is important to maintain a normal body temperature to keep normal physiological function. Medical practitioners should be aware that low body temperature is a manifestation of adrenocortical insufficiency and that it is treatable.

In a standard internal medicine textbook, adrenocortical insufficiency is listed as a differential diagnosis of hypothermia; ${ }^{3}$ however, no reference was listed and we could not find any articles in PubMed reporting on this case occurring in human subjects. One report stated that $8(80 \%)$ of 10 cats with adrenocortical insufficiency exhibited hypothermia. ${ }^{4}$ However, our present study is the first report that examines the relationship between adrenocortical insufficiency and low body temperature in human subjects.

\section{Limitations of the present study}

The limitations of the present study are described as follows: First, the number of patients was small $(n=15)$, so further studies are needed to validate the results. Second, normal daily temperature variation is typically around $0.5^{\circ} \mathrm{C}$, low in the morning and high in the evening. ${ }^{3}$ In the present study, the body temperature at discharge was measured in the morning. However, the body temperatures at admission included a mixture of measurements in the morning, at noon, in the evening, and at night. That is, the body temperature measurement at admission was not standardized. However, if we restricted our cohort to only those patients who were admitted in the morning, the mean body temperature at admission would have been lower than that in the present study, because body temperatures in the morning are normally low. As a result, the difference between the body temperature at admission and that at discharge would have been greater than that in the present study. Therefore, we need not change our conclusion: glucocorticoid administration increased the body temperatures of the patients with adrenocortical insufficiency.

In the present study, most of the patients with adrenocortical insufficiency manifested low body temperatures with or without inflammation. Inflammation had little effect on the body temperatures. However, glucocorticoid administration significantly increased the body temperature of the patients with adrenocortical insufficiency. Medical practitioners should take into account the relationship between low body temperature and adrenocortical insufficiency.

\section{References}

1. Henry K, Shlomo M, Kenneth P, Reed L. Williams textbook of endocrinology. 11th edition. Philadelphia: Saunders; 2007. p 366.

2. Leslie J, De Groot J, Jameson L. Endocrinology. 5th ed. Philadelphia: Saunders; 2005. p 2346.

3. Fauci A, Braunwald E, Kasper D, et al. Harrison's principles of internal medicine. 17th ed. Chicago: McGraw-Hill Professional; 2008. p 117, 135.

4. Peterson ME, Greco DS, Orth DN. Primary hypoadrenocorticism in ten cats. J Vet Intern Med 1989;3:55-8. 